\title{
Conceptual modeling for requirements of government to citizen service provision
}

Book or Report Section

Accepted Version

Sun, L., Mushi, C. J. and Alsoud, A. (2011) Conceptual modeling for requirements of government to citizen service provision. In: Pokorny, J., Repa, V., Richta, K., Wojtkowski, W., Linger, H., Barry, C. and Lang, M. (eds.) Information Systems Development: Business Systems and Services: Modeling and Development. Springer, pp. 747-758. ISBN 9781441996459 doi: https://doi.org/10.1007/978-1-4419-97906_60 Available at http://centaur.reading.ac.uk/24899/

It is advisable to refer to the publisher's version if you intend to cite from the work. See Guidance on citing.

To link to this article DOI: http://dx.doi.org/10.1007/978-1-4419-9790-6_60

Publisher: Springer

All outputs in CentAUR are protected by Intellectual Property Rights law, including copyright law. Copyright and IPR is retained by the creators or other 
copyright holders. Terms and conditions for use of this material are defined in the End User Agreement.

\section{www.reading.ac.uk/centaur}

\section{CentAUR}

Central Archive at the University of Reading

Reading's research outputs online 


\title{
Conceptual Modelling for Requirements of Government to Citizen Service Provision
}

\author{
Lily Sun ${ }^{1}$, Cleopa John Mushi ${ }^{2}$ and Anas Alsoud ${ }^{3}$
}

\begin{abstract}
Government to citizen (G2C) service provision is demanded to fit for purpose for users. A process of finding services from a G2C system involves understanding of the user's request, selecting the relevant services, and deciding amongst the candidate services to meet the user's needs. Some current approaches, such as benchmarking methods, are capable of measuring the service quality in the quantitative manner. However, G2C services also have intangible features which can be measured qualitatively. In this paper, a method is described to model the requirements of $\mathrm{G} 2 \mathrm{C}$ services and their provision. To facilitate a service provision process, a set of criteria is identified and used to ensure the quality of the resultant services. An ontology model developed represents requirements of service provision in a web service environment that involves service consumers, service providers, and service advisor. Interactions between these stakeholders are defined by norms which generate workflows for executing the functions in the techniques. An experiment using DEA is carried out in this paper based on quantitative criteria to validate the method and its techniques, i.e. articulates, derives and pre-selects. The pre-selected services as the candidates are further evaluated with the contribution of the qualitative features of the services by using analytical hierarchical process (AHP) to decide for winning services.
\end{abstract}

\section{Introduction}

Government to citizen (G2C) service provision can be defined as an execution of public services to citizens (i.e. users) that involves various service providers

\footnotetext{
${ }^{1}$ Lily Sun

School of Systems Engineering, University of Reading, Whiteknights, Reading, RG6 6AY, UK

Email: lily.sun@reading.ac.uk.

${ }^{2}$ Cleopa John Mushi

School of Systems Engineering, University of Reading, Whiteknights, Reading, RG6 6AY, UK

Email: c.j.s.k.mushi@reading.ac.uk.

${ }^{3}$ Anas Alsoud

Informatics Research Centre, University of Reading, Whiteknights, Reading, RG6 6WB, UK

Email: a.alsoud@student.reading.ac.uk.
} 
through information and communication technologies (ICT) [2]. As the services become widely online available, the user is also becoming more demanding for fit for purpose services to be provided. This requires an effective approach to benchmark the quality of G2C services and assist in an optimisation process for a right choice of the service [18]. However, identifying a suitable service provided by a pool of providers needs an approach to recognise citizens' personalised needs and their needs change. This paper presents an ontology model with a set of techniques that enable a multi-criteria decision making process to provide fit for purpose services to meet citizen requirements in the e-government setting. This model incorporates citizen and service provider profiles which define citizen and service provision requirements. Norms are also built in the model to facilitate a systematic service selection and optimisation process.

The remainder of the paper is organised as follows. Section 2 discusses current trend in measuring quality of $\mathrm{G} 2 \mathrm{C}$ service provision and also techniques that can be used in selecting the optimum service requested. Section 3 presents an ontology model with the embedded norm engine which facilitates the requirements analysis for service provision. Section 4 illustrates how the techniques in the ontology model are applied to assist the pre-selection of candidate services and optimise winning services. Section 5 draws conclusion and recommendations for the further work.

\section{Related work}

\subsection{G2C service provision}

Currently, web service approach has been adopted by the G2C systems, e.g. DirectGov. Web services support three functions; service description and publishing, service discovery, and service interaction and consumption. Service providers are the ones responsible for publishing their services in the registry from which service consumers can locate and invoke services. The registry (or a public repository) is a public directory containing information about the services and the service providers from diverse sources in a unified way [20]. Web Service driven $\mathrm{G} 2 \mathrm{C}$ systems can provide a seamless applications integration that allows the services to be loosely coupled and re-useable across organisational boundaries and from multiple providers via a public repository [17]. However, the current G2C systems are provider-centric by imposing G2C services to be passively provided to users [19]. There are demands for transferring the provider driven approach on to a citizen-centred approach. In a development of citizen driven G2C systems, services should be discovered to meet the user's needs. The traditional web service approach is, to certain extent, able to capture the user's requirements, but the service finding process lacks the capability of comprehensive selection and optimisation of the suitable services. Such capability can not be achieved by keywords matching and smart text mining for similarity, this requires a holistic domain 
knowledge understanding and representation of $\mathrm{G} 2 \mathrm{C}$ service provision. A service register in web services should act as a service advisor which applies the underpinning service provision strategies and criteria for service discovery.

The European Commission (EC) defines the G2C services into 12 areas; income taxes, job search, social security benefits, personal documents, car registration, application for building permission, declaration to the police, public libraries, birth \& marriage certificates, enrolment in higher education, announcement of moving, and health-related services [5]. It is challenging that a G2C system accomplishes these service provisions via ICT [12], because the dynamic G2C interactivity with complete routine tasks can be sophisticated from both the service providers and users. There is lack of knowledge representation on how to advise quality services offered by the provider to the user. Quality of service in this work is defined through an ontological representation in meeting user needs who expresses a request in the context of higher education service provision. The work extends current e-Government benchmarking approaches by incorporating qualitative criteria in measuring service quality and applying the process of meeting user needs in a web-service environment.

\subsection{Service selection and ranking methods}

DEA is a linear programming algorithm that has been used successfully in determining the best-practice production frontier relative to individual firms or decision making units (DMUs). In DEA, performance efficiency is measured by a weighted sum of outputs to a weighted sum of inputs for a particular DMU [6][1]. A DMU represents a service provider who in a pre-selection stage is competitively measured against other providers on their overall performance based on a set of criteria that have been developed. A resultant efficiency, $h_{o}$, from DEA is normally decided by either maximizing outputs or minimizing inputs. In our work, maximizing outputs will be considered. DEA is capable of discovering those DMUs which hold a range of value of $h_{o}$ based on the selection criteria. For those DMUs which satisfy $h_{o}=1$, they need to be further decided as a winning DMU for the request. AHP, therefore, is used to assist for such decision making [1][15].

AHP is a multi-criteria decision making (ranking and optimising) algorithm which enables decision makers who are faced with making numerous and conflicting evaluations to derive a way to come to a compromise [3][4]. In a set of criteria, each criterion is assigned with significant attribute and each pair of alternatives can be judged by comparing between criteria. Once each comparison has been carried out through all the determining criteria, a winning DMU can be selected. 


\section{Modeling requirements of $\mathrm{G} 2 \mathrm{C}$ service provision}

G2C service provision is a knowledge sharing process which requires understanding and representation of the concerns of stakeholders (including users, service providers and service advisor) [11]. An ontological modelling [10] is adopted to define the patterns of behaviour in such a process where various agents with their roles and relationships are involved as well as the norms that govern the service provision workflow.

\subsection{Ontological modelling for the Requirements of Service Provision}

An ontology model, as shown in Fig. 1, depicts the knowledge of G2C service provision. The model comprises of a set of semantic units, each of which is normally formed by the basic concepts of agent, role, affordance, and determiner [14][9]. An agent is drawn with a shape of an ellipse and represents a stakeholder such as an individual (person), a group (organisation) or a community (nation, society). Affordance is represented with a rectangle and depicts the relationships of entities and observable pattern of behaviour occurring within a context [10]. An affordance forms a semantic unit with a maximum of two antecedents (the concepts on the left end of the line) so as to maintain a concise and stable ontology structure. From the model then, different agents are involved in service provision with various roles such as citizen, provider, service advisor and central government, which represent responsibilities defined by the corresponding affordances.

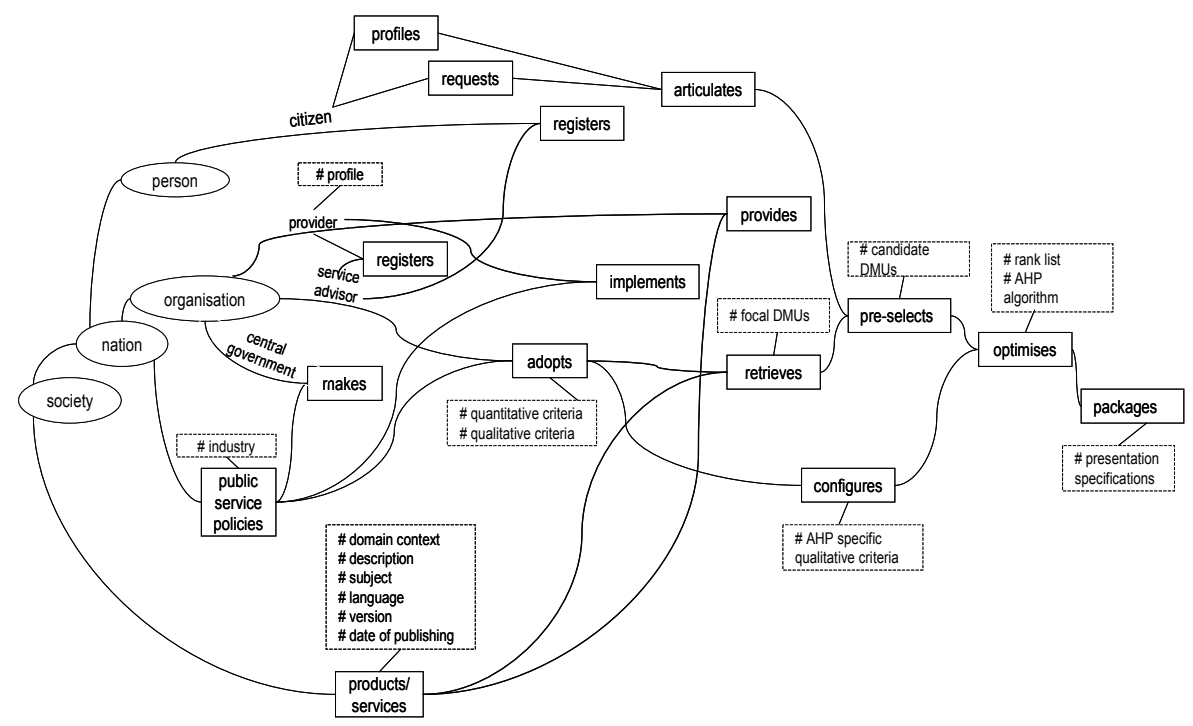

Fig. 1 An ontologv model of G2C service provision 
All these responsibilities have direct or indirect relations with products/services modelled in the ontology. For example, the affordance of provides has two antecedents, i.e. organisation and products/services. The antecedent of products/services describes the type of G2C provision and the organisation with the role of provider provides the $\mathrm{G} 2 \mathrm{C}$ services. This semantic unit ensures the service being provided complies with the public service policies made by the government. With the affordance of retrieves, there are two antecedents of adopts and products/services. The antecedent of adopts defines the quantitative and qualitative criteria based on public service policies for a particular industry that are adopted by the organisation in the role of service advisor. The antecedent of adopts ensures that there is no conflict of attributes in the retrieves process. For example, in universities, sponsorships are available for full-time postgraduate courses only. This therefore resolves conflicts concerning criteria for course duration, mode of study and finance. The retrieves process then contains the focal DMUs with their capabilities in service provision described by the quantitative and qualitative criteria that are defined from adopting the public service policies. So, in order to provide a personalised service/product, the model pays special attention to the quality of service provision based on service specification which involves articulation of requests of service and citizen's profile leading into a preselection process with retrieves.

The ontology model therefore integrates the requirements for user, service provider, and service advisor with the defined role of citizen, provider and service advisor respectively. Each registered citizen has a profile which is used to articulate a request for services made to service advisor, particularly if the request is fuzzy. For example, if a citizen requests for a service of course in Higher Education and this user has some degree of disability. In this case, personal information in the citizen profile will assist to specify the requirements specifications for selecting the service which meets the user's needs. The affordance of pre-selects is the one that performs the selection process, and it is ontologically dependant on articulates and retrieves - the former specifying citizen's request, the latter the DMUs and their capabilities in providing the services.

\subsection{Criteria for measuring the quality of services}

The quality of service is largely determined by the service provider who has the reputed capability and competence to offer their services. In order to benchmark service providers for their performance and capability, each registered service provider is described in a provider's profile (see Fig. 2). The profile contains the details of a service provider and involves units which provide services. A Portfolio describes the capability of the service provision and the quality of the service meeting users' demands. Provider profile assists an identification of focal DMUs while a service provider is being benchmarked in a pre-selection process. This profile also possesses the measures for finding candidate services according to a service request. Table 1 details the service quality measures in the form of criteria. 


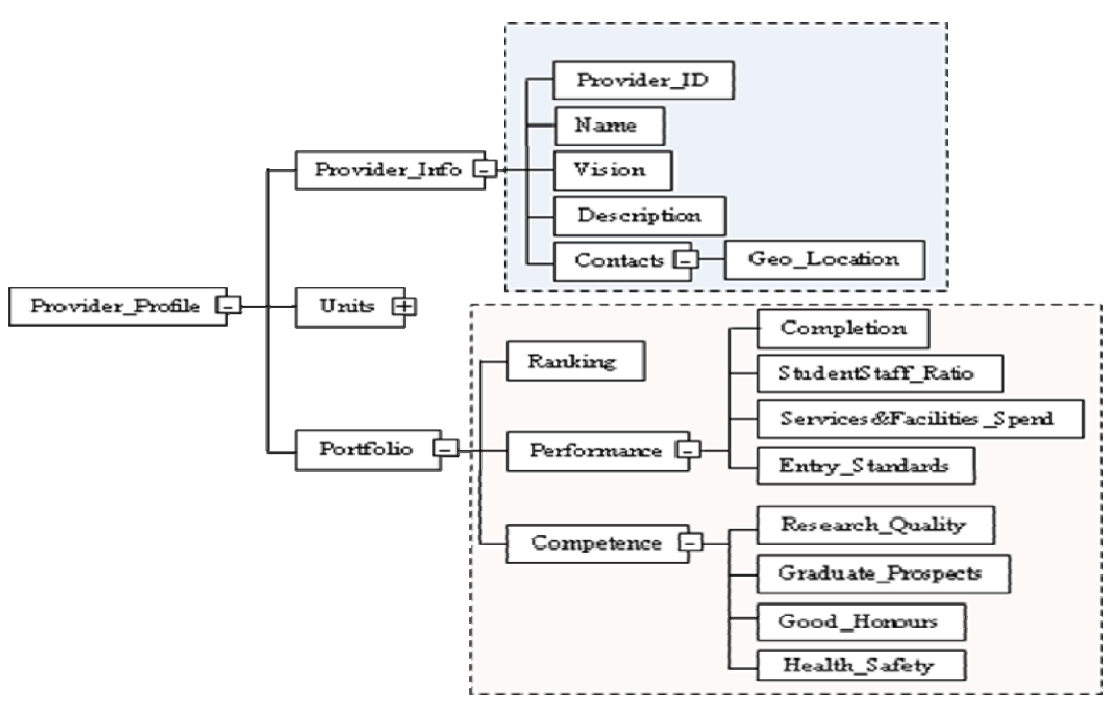

Fig. 2 Service provider profile

A service schema in Fig. 3 defines the features and properties of the concept of products/services in the ontology model. This schema also captures the criteria in Table 1 for assessing a service. Those service specific criteria can be used to benchmark the quality of the services in conjunction with the provider specific criteria. A set of metadata, such as domain context, description, and language can assist a discovery of the products/services.

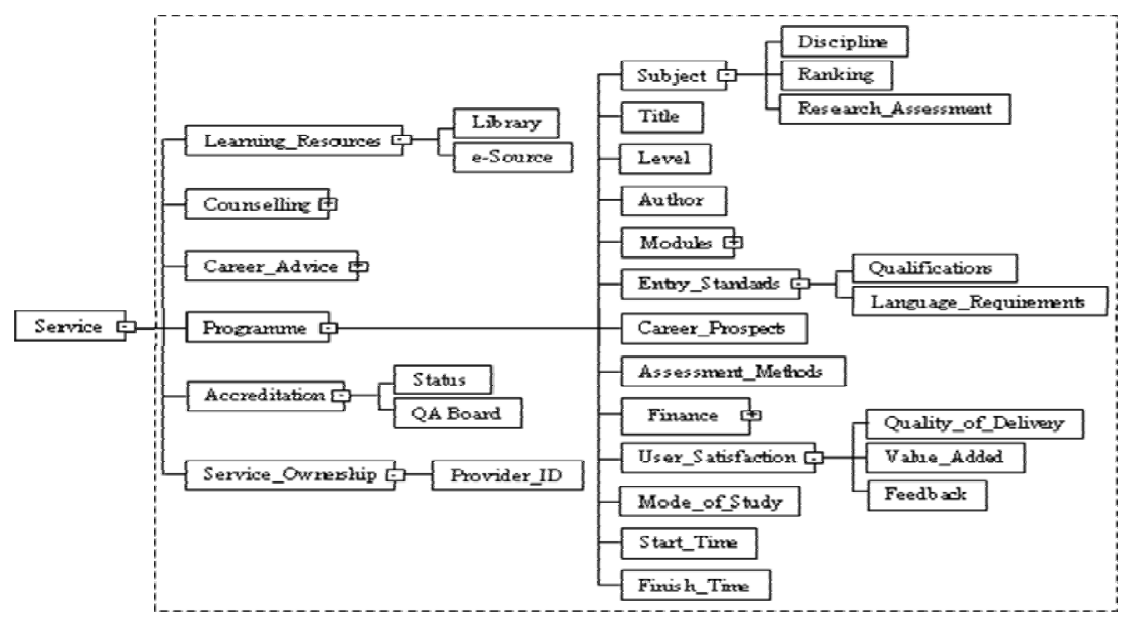

Fig. 3 Service Schema 
Table 1 Criteria for selecting the relevant service

\begin{tabular}{|c|c|c|c|}
\hline Criteria & Sub-criteria & Type & Description \\
\hline \multirow{15}{*}{ Quality } & Provider ranking & Quantitative & Overall performance \\
\hline & Subject ranking & Quantitative & Subject performance \\
\hline & $\begin{array}{l}\text { Quality of } \\
\text { delivery }\end{array}$ & Quantitative & $\begin{array}{l}\text { Student views on the teaching quality of } \\
\text { the subject }\end{array}$ \\
\hline & $\begin{array}{l}\text { Research } \\
\text { assessment }\end{array}$ & Quantitative & Research quality and innovation \\
\hline & Entry standards & Quantitative & Requirements for admission of a subject \\
\hline & Career prospects & Qualitative & $\begin{array}{l}\text { Job opportunities and positions for } \\
\text { graduates }\end{array}$ \\
\hline & $\begin{array}{l}\text { Graduate } \\
\text { prospects }\end{array}$ & Quantitative & Destinations of subject graduates \\
\hline & $\begin{array}{l}\text { Student-staff- } \\
\text { ratio }\end{array}$ & Quantitative & Average staffing level for the subject \\
\hline & Good honours & Quantitative & $\begin{array}{l}\text { Percentage of graduates achieving a first } \\
\text { or upper second }\end{array}$ \\
\hline & Alumni & Qualitative & Experience of graduates \\
\hline & Accreditation & Qualitative & $\begin{array}{l}\text { Reviewed status of institution quality by } \\
\text { authorities }\end{array}$ \\
\hline & $\begin{array}{l}\text { Assessment } \\
\text { methods }\end{array}$ & Qualitative & $\begin{array}{l}\text { Ways by which learning outcomes being } \\
\text { assessed }\end{array}$ \\
\hline & Value added & Quantitative & $\begin{array}{l}\text { Student level of achievement from the } \\
\text { course }\end{array}$ \\
\hline & Feedback & Quantitative & $\begin{array}{l}\text { Student judgement of quality of subject } \\
\text { they have studied }\end{array}$ \\
\hline & $\begin{array}{l}\text { Disability } \\
\text { services }\end{array}$ & Qualitative & $\begin{array}{l}\text { Means by which various disabilities can } \\
\text { be supported }\end{array}$ \\
\hline \multirow{4}{*}{ Finance } & $\begin{array}{l}\text { Academic } \\
\text { service spend }\end{array}$ & Quantitative & $\begin{array}{l}\text { Expenditure per student on all academic } \\
\text { services }\end{array}$ \\
\hline & Facilities spend & Quantitative & $\begin{array}{l}\text { Expenditure per student on staff and } \\
\text { student facilities }\end{array}$ \\
\hline & Tuition & Quantitative & $\begin{array}{l}\text { Monetary value to studying the program } \\
\text { per academic year }\end{array}$ \\
\hline & $\begin{array}{l}\text { Financial } \\
\text { support }\end{array}$ & Qualitative & $\begin{array}{l}\text { Bursary, sponsorships and funding for } \\
\text { the course }\end{array}$ \\
\hline \multirow[b]{2}{*}{ Flexibility } & Mode of study & Quantitative & Full-time/part-time/distance learning \\
\hline & $\begin{array}{l}\text { Academic } \\
\text { calendar }\end{array}$ & Quantitative & Different starting dates of the course \\
\hline Geog. Location & Country & Quantitative & The country where the service is offered \\
\hline
\end{tabular}

\subsection{Norms defining the service provision process}

In order to systematically perform a service provision process, norm engine acts as a control mechanism to govern the behaviour of cause of actions. In the ontology model, each affordance of the semantic unit is associated with a period of existence which can be defined by a pair of startNorm and finishNorm. During the existence, operationalNorm describes its pattern of behaviour. For 


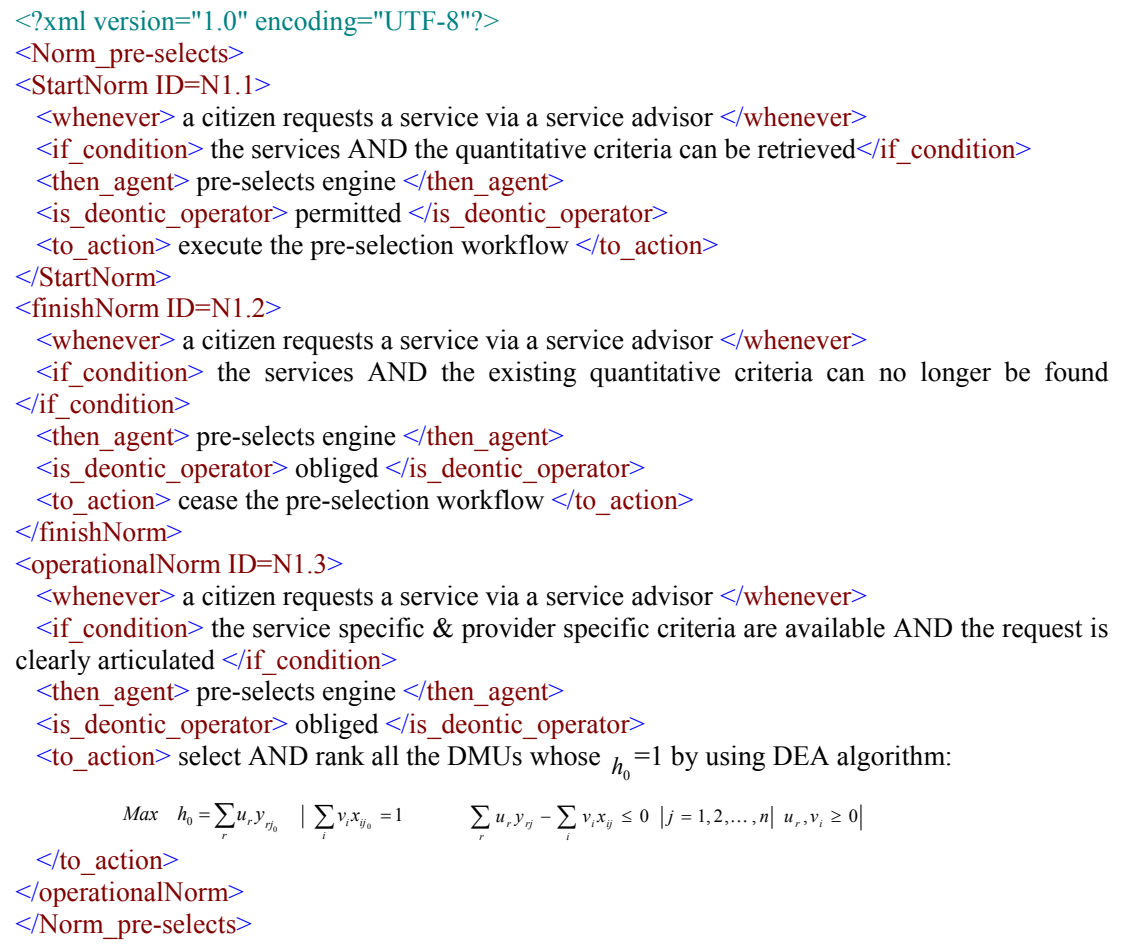

Fig. 4 The norms defining the pre-selects process

example, the startNorm and finishNorm define the pre-selects existence and its cease (see Fig. 4). The operationalNorm specifies the DEA algorithm that takes multiple input and multiple output quantitative criteria for selecting all competitive DMUs based on their maximum efficiencies, i.e. $h_{o}=1$. The operational norms are normally defined for generating a workflow of each affordance in the semantic unit. The result from the left semantic unit is carried over as the input to the workflow in the right semantic unit. All the workflows can be integrated to structure the entire service provision process.

\section{Application and discussion of the ontology model}

The ontology model and the techniques are validated through various simulations towards the selected service requests. A service selection process normally starts from a service request. For example, a person with the role of citizen requesting for a higher education programme, e.g. a master course in Computer Science from a top 10 university in the UK that starts from October and also offers studentships. Based on the request, the articulates deduces a set of multiple criteria of \{Geo_Location, Ranking, Graduate_Prospects, Entry_Standards, Good_Honours, Completion $\}$ from the provider's profile as well as \{Title, Ranking, En- 
try_Standards, Career_Prospects, Graduate_Prospects, Financial_Support, Level, Start_Time, Quality_of_Delivery, Value_Added, Feedback\} from the service schema. Each of these criteria is assigned with a weight which is determined by the requestor's preference in conjunction with the pre-defined domain rules. The pre-selects then uses the criteria to discover the DMUs. There are two sets of results produced to represent the quality of the service on the basis of institutional and subject level respectively (see Table 2 and Table 3). The results in Table 2

Table 2 The consolidated results for the DMUs based on provider rankings

\begin{tabular}{|l|l|l|l|l|l|l|l|l|}
\hline \multicolumn{3}{|l|}{ INPUT } & \multicolumn{1}{l|}{ OUTPUT } \\
\hline DMU & $\begin{array}{l}\text { Provider } \\
\text { Ranking }\end{array}$ & $\begin{array}{l}\text { Entry } \\
\text { Standards }\end{array}$ & Completion & $\begin{array}{l}\text { Good } \\
\text { Honours }\end{array}$ & W/O & W/I & Efficiency & Working \\
\hline INS-037 & 5 & 0.4732 & 1.0000 & 0.7990 & 0.9699 & 1.0000 & 0.9699 & -0.0301 \\
\hline INS-085 & 3 & 0.5045 & 1.0000 & 0.7062 & 0.8960 & 1.0000 & 0.8960 & -0.1040 \\
\hline INS-118 & 9 & 0.4588 & 1.0000 & 0.7823 & 0.9871 & 1.0000 & 0.9871 & -0.0129 \\
\hline INS-133 & 1 & 0.5346 & 1.0000 & 0.9296 & 0.9561 & 1.0000 & 0.9561 & -0.0439 \\
\hline INS-222 & 7 & 0.4978 & 1.0000 & 0.9053 & 1.0000 & 1.0000 & 1.0000 & 0.0000 \\
\hline INS-366 & 4 & 0.5031 & 1.0000 & 0.7917 & 0.9069 & 1.0000 & 0.9069 & -0.0931 \\
\hline INS-424 & 2 & 0.5439 & 1.0000 & 0.8788 & 0.8973 & 1.0000 & 0.8973 & -0.1027 \\
\hline INS-522 & 6 & 0.4823 & 1.0000 & 0.8302 & 0.9752 & 1.0000 & 0.9752 & -0.0248 \\
\hline INS-847 & 10 & 0.4521 & 1.0000 & 0.7802 & 1.0000 & 1.0000 & 1.0000 & 0.0000 \\
\hline INS-975 & 8 & 0.4914 & 1.0000 & 0.8739 & 0.9896 & 1.0000 & 0.9896 & -0.0104 \\
\hline
\end{tabular}

show that only INS-222 and INS-847 satisfy the maximum efficiency, i.e. $h_{o}=1$ and also fall into top 10 institutional ranking [7][8] that primarily meet the user's request. The working column shows the difference between weighted output $(\mathrm{W} / \mathrm{O})$ and weighted input $(\mathrm{W} / \mathrm{I})$ as constraint derived from, $\sum_{r} u_{r} y_{r j}-\sum_{i} v_{i} x_{i j} \leq 0$, where $j=1,2, \ldots, n$ and $u_{r}, v_{i} \geq 0$. The results in Table 3

Table 3 The consolidated results for the DMUs based on subject rankings

\begin{tabular}{|l|c|c|c|c|c|c|c|c|}
\hline DMU & $\begin{array}{l}\text { Subject } \\
\text { Ranking }\end{array}$ & $\begin{array}{l}\text { Provider } \\
\text { Ranking }\end{array}$ & $\begin{array}{l}\text { Entry } \\
\text { Standards }\end{array}$ & $\begin{array}{l}\text { Quality of } \\
\text { Delivery }\end{array}$ & $\begin{array}{l}\text { Value } \\
\text { Added }\end{array}$ & Feedback & $\begin{array}{l}\text { Graduate } \\
\text { Prospects }\end{array}$ & Efficiency \\
\hline INS-037 & 31 & 5 & 0.4614 & 0.7500 & 0.0341 & 0.4659 & 1.0000 & 1.0000 \\
\hline INS-085 & 7 & 3 & 0.4915 & 0.8723 & 0.0319 & 0.6277 & 1.0000 & 1.0000 \\
\hline INS-118 & 18 & 9 & 0.5256 & 0.9634 & 0.0610 & 0.7073 & 1.0000 & 0.9838 \\
\hline INS-133 & 1 & 1 & 0.9566 & 0.9566 & 0.0361 & 0.6831 & 1.0000 & 0.9222 \\
\hline INS-222 & 2 & 7 & 0.4915 & 0.9314 & 0.0704 & 0.6651 & 1.0000 & 1.0000 \\
\hline INS-424 & 3 & 2 & 0.6359 & 0.9565 & 0.0217 & 0.8152 & 1.0000 & 1.0000 \\
\hline INS-522 & 5 & 6 & 0.5554 & 1.0000 & 0.0482 & 0.7952 & 1.0000 & 1.0000 \\
\hline INS-847 & 8 & 10 & 0.4943 & 1.0000 & 0.0455 & 0.5114 & 0.9091 & 0.8754 \\
\hline INS-975 & 26 & 8 & 0.5063 & 0.8750 & 0.0500 & 0.6625 & 1.0000 & 1.0000 \\
\hline
\end{tabular}


present the subject quality measures independently from the general performance of the institutions. It is observed that a subject ranking position many not be the same as its provider's. By comparing these two sets of results, it is expected to identify a discrepancy, particularly when there is no link between them at all.

Based on the subject ranking, 6 out of 9 institutions satisfy the maximum efficiency with INS-222 achieving the maximum efficiency in both provider and subject rankings. The two sets of results suggest 1) getting an optimum result based on the subject of interest from the pre-selected institutions, i.e. INS-037, INS-085, INS-222, INS-424, INS-522 and INS-975; 2) considering the institution which has been pre-selected in both cases, i.e. INS-222; or 3) getting an optimum result based on the pre-selected institutional rankings. To follow the third suggestion which is the original user request, the list of the candidate DMUs produced by pre-selects is further analysed for optimisation. The affordance of optimises determines the winning service by using the AHP algorithm with specific qualitative criteria, i.e. Financial_Support, Career_Prospects, Provider_Ranking and Subject_Ranking. Fig. 5 represents the decision tree for multi-criteria evaluation. In

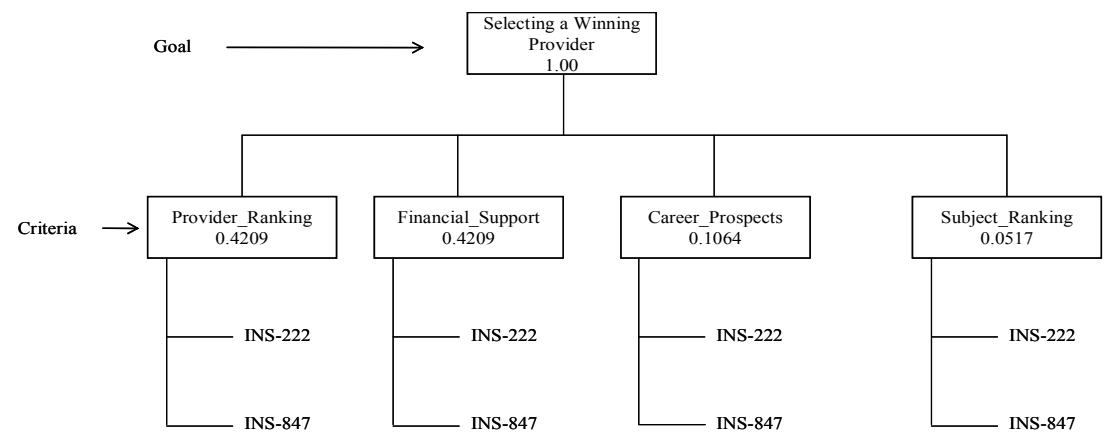

Fig. 5. The decision tree with the criteria weights

order to ensure a consistency in prioritisation, consistence ratio $C R=C I / R I$ is computed. $C I$ represents consistency index,$\lambda_{\max }-n / n$, where $\lambda_{\max }$ is the principal eigen value, $n$ is the number of pair-wise comparison matrix, and $R I$ is Random consistency Index. In this simulation, $C R=2.72 \%$ shows that the preferences for 4 criteria are consistently evaluated, i.e. $C R \leq 10 \%$ [13][16]. Due to the user request, Provider_Ranking and Financial_Support are assigned more weights.

AHP computation shows that Subject_Ranking has very little significance (i.e. 0.0517) compared to the others. Therefore, it was ignored in the further computation. Consequently, the weights for the other three criteria have to be readjusted, such as 0.4439 for Provider_Ranking, 0.4439 for Financial_Support, and 0.1122 for Career_Prospects. Table 4 consolidates the overall composite weights of the two DMUs and INS-222 satisfies the user's request. 
Table 4 Overall composite weights of the alternatives

\begin{tabular}{|l|c|c|c|c|c|}
\hline & Provider_Ranking & Financial_Support & Career_Prospects & Composite_Weight & Rank \\
\hline $\begin{array}{l}\text { Adjusted } \\
\text { Weights }\end{array}$ & 0.4439 & 0.4439 & 0.1122 & 1.0000 & \\
\hline INS-222 & 0.8333 & 0.2500 & 0.5000 & 0.5370 & 1 \\
\hline INS-847 & 0.1667 & 0.7500 & 0.5000 & 0.4630 & 2 \\
\hline
\end{tabular}

\section{Conclusion and future work}

G2C service provision presents a complex problem domain that demands a method to model requirements of service provision. This research work has proposed the use of ontology model for conceptualising the domain knowledge where citizen requirements are presented from the aspect of social domain. The ontology model presents very well the concept of web service with different stakeholders such as service advisor, central government, and service providers interacting to ensure that quality of $\mathrm{G} 2 \mathrm{C}$ service provision is maintained. Profiles were also created to facilitate articulation of requests and to support for personalised service provision. Service schema was developed to illustrate different attributes and criteria for the service provided. Norms were embedded in the model for the execution of a pre-selection workflow. DEA has been applied to implement pre-selects process due to the multi-criteria nature of the problem domain which also exhibits multiple output and multiple input service criteria. The results indicate that DEA has been effective in selecting suitable services that can meet citizen request.

The model also provides for alternative suggestions to the user to capture intentions and what can also be provided in line with the user request which the user might not be aware. This forms the intelligent part of the system which calls for further work. To process further the request from pre-selection, an evaluation was conducted to compare the differences between the needed qualitative criteria of the selected service providers. AHP was used as a mechanism to prioritise the selected services based on weighting and the optimum service candidate capable of meeting citizen requirements was identified. Future works will also need to identify mechanism to assist the selection in the problem domain through matching cases, and to develop a CASE tool to facilitate consistent documentation.

\section{References}

1. Azadeh A, Ghaderi SF, Izadbakhsh H (2008) Integration of DEA and AHP with Computer Simulation of railway systems improvement and optimization. Journal of Applied Mathematics and Computation 195: 775-785

2. Bekkers V, Homburg V (2005) E-government as an Information Ecology: Backgrounds and Concepts. In: Bekkers V, Homburg V (eds.) E-Government as Institutional and Technological Innovation in Public Administration, pp. 1-20. IOS Press, Amsterdam 
3. Benyoucef M, Canbolat M (2007) AHP-Based Supplier Selection in E-Procurement. International Journal of Services and Operations Management 3: 172-192

4. Chen CT, Lin CT, Huang SF (2006) A Fuzzy Approach for Supplier Evaluation and Selection in Supply Chain Management. International Journal of Production Economics 102: 289-301

5. Graafland-Essers I, Ettedgui E (2003) Statistical Indicators Benchmarking the Information Society. Benchmarking e-Government in Europe and the US

6. Hasan AM, Shankar R, Sarkis J (2008) Supplier Selection in an Agile Manufacturing Environment Using Data Envelopment Analysis and Analytical Network Process. International Journal of Logistics Systems and Management 4: 523-550

7. The Sunday Times University Guide (2010) University Rankings League Tables. http://extras.timesonline.co.uk/tol gug/. Accessed 04 Mar 2010

8. The Complete University Guide (2010) University League Tables 2010. http://www.thecompleteuniversityguide.co.uk/. 04 Mar 2010

9. Liu K (2000) Semiotics in Information Systems Engineering. Cambridge University Press, Cambridge.

10. Liu K, Sun L, Fu Y (2008) Ontological modelling of content management and provision. Journal of Information and Software Technology 50: 1155-1164

11. Liu K, Clarke RJ, Andersen PB, Stamper, RK (2001) Information, Organisation and Technology: Studies in Organisational Semiotics. Kluwer, Boston.

12. Ronagham SA (2002) Benchmarking E-Government: A Global Perspective, New York.

13. Saaty TL (1990) Eigenvector and Logarithmic Least Squares. European Journal of Operational Research 48: 156-160

14. Sun L, Ousmanou K, Cross M (2008) An Ontological Modelling of User Requirements for Personalised Information Provision. Journal of Information Systems Frontiers $12: 337-357$

15. Sung HH, Krishnan R (2008) A Hybrid Approach to Supplier Selection for the Maintenance of a Competitive Supply Chain. Journal of Expert Systems with Applications 34: 1303-1311

16. Tan PS, Lee EW, Mous K, Lee SSG, Goh AES (2008) Multi-Criteria, ContextEnabled B2B Partner Selection. IEEE International Conference on Systems, Man and Cybernetics doi: 10.1109/ICSMC.2008.4811533

17. van Thanh D, Jorstad I (2005) A service-oriented architecture framework for mobile services. Proceedings of the Advanced Industrial Conference on Telecommunications/Service Assurance with Partial and Intermittent Resources Conference/ELearning on Telecommunications Workshop (AICT/SAPIR/ELETE'05), pp.65-70

18. von Lucke J, Reinemann H (2000) Speyerer Definition von Electronic Government, http://foev.dhv-speyer.de/ruvii/Sp-EGov.pdf. Accessed 25 March 2010

19. Wang H, Huang JZ, Qu Y, Xie J (2004) Web Services: Problems and Future Directions. Journal of Web Semantics 1: 309-320

20. Zou G, Xiang Y, Gan Y, Wang D, Liu Z (2009) An Agent-Based Web Service Selection and Ranking Framework with QoS. $2^{\text {nd }}$ IEEE International Conference on Computer Science and Information Technology doi: http://doi.ieeecomputersociety.org/10.119/ICCSIT.2009.5234607 